Cheryl R. Ganz

\title{
Fan Dancing and Fan Belts: Selling Optimism at the 1933 Chicago World's Fair
}

IN 1833, CHICAGO WAS A TINY BACKWOODS SETTLEMENT on the western frontier. It ranked as the world's fourth largest city a century later. To celebrate the city's remarkable rise, civic leaders and businessmen decided to host the city's second world's fair. The theme of this 1933-34 international exposition was "A Century of Progress." Amazingly, in the midst of the Great Depression, this celebration championed corporate capitalism - the very culprit that many Americans blamed for their economic woes. The fair celebrated the advances of science and its application to consumer goods. Unlike earlier world's fairs, this international venue de-emphasized the creativity of individual entrepreneurs by replacing competitive exhibits in thematic halls with noncompetitive and corporate-sponsored pavilions. ${ }^{1}$

While doing research on the 1933 Chicago World's Fair, I visited over thirty libraries and archives to find the pieces of the historical puzzle that would come together to help create a picture presenting not only the iconic vision of the fair, but also revealing untold stories that made this exposition exceptional for its time. But to do so, I had to expand my research beyond books and magazines about the fair, secondary sources that provided context, and original manuscripts from the fair's management. Those resources left too many gaps in the story. And so I began to search for ephemera from the fair: postcards, mail, photographs, newsletters, souvenirs, scrapbooks, brochures from exhibits, and café menus.

Despite the economic woes of the Great Depression, most fairgoers carried home small treasures to spark their good memories, which they kept for a lifetime, passing them on to the next generation, along with stories of this very exciting moment in their lives. The notes jotted on postcards gave first-hand accounts of the visitors' experiences. Photographs in scrapbooks revealed the interiors of buildings, views missing from the promotional materials produced before the fair opened.

1. See Cheryl R. Ganz, The 1933 Chicago World's Fair: A Century of Progress (Urbana: University of Illinois Press, forthcoming 2008). 
Complimentary brochures distributed by the business exhibits provided insights into marketing a corporate image. Souvenirs from the Midway told how Americans desperately needed fun to counterbalance the struggles of the 1930s. And guidebooks and knick-knacks displayed in homes seventy years later exposed the magic this fair held for so many attendees and the optimism they took back to their communities and businesses.

I began my search for fair ephemera and memorabilia at flea markets, antique shops and shows, and postcard and stamp bourses. More recently, the online auction eBay has not only unearthed sources previously unimagined but has also served as a pricing guide for various ephemera. From 1933 to 1935, J.K. Wilcox of the John Crerar Library in Chicago compiled three checklists of fair publications and handouts. Although never updated with new discoveries, these checklists alone show that fair visitors had access to more than a thousand brochures, pamphlets, and printed handouts - most of them complimentary. To research the 1933-34 Chicago World's Fair without a serious study of this ephemera would leave a major gap in understanding its impact and the visitor experience.

Chicago benefited from the fair economically, but big business had its own reasons for spending considerable funds for visibility at the fair-funds crucial to fair organizers, who had decided from the very beginning to make it the first world's fair to operate without government subsidy. Corporations sought to restore the respect and credibility that corporate leadership had lost following Black Tuesday. In the midst of the nation's most severe depression, American industry invested thirtytwo million dollars as exhibitors in the fair: twenty million in 1933 and twelve million more in the following year. As a result, the frontage of exhibits extended over eighty miles, bombarding fairgoers with visions of industrial progress during the past century, and with optimism that the quality of life would continue to improve in incremental steps toward a utopia founded on science and technology.

Fair organizers and financial backers envisioned "A Century of Progress" as a new exposition for a new era. Along the lakefront, museums offered visitors permanent structures with exhibits reminiscent of the old-time expositions. But organizers sought to incorporate them into a fresh, new fair experience rather than merely revisit earlier expositions. They knew that museums alone would not draw the crowds, but that people would flock to see a show. Furthermore, they wanted to shift away from the old fair model that used separate buildings to showcase competitive industrial wares from individual states and nations. Given the depressed economy, the old model would surely fail, if for no other reason than lack of funds. This left the door open for fair organizers and corporate leaders to exemplify their modernist vision through art, architecture, advertising, industrial design, and 
exhibits illustrating the cooperative progress of industry, and to proclaim hope and optimism in their fair theme of "progress."

Crucial to public relations during the Depression, this world's fair offered an opportunity for science, industry, and invested capital to tell their stories of service to the public, and to position themselves as national leaders confident of a prosperous future. If dramatic exhibits could demonstrate to average Americans how scientific applications and technological advances had improved the material condition of their lives, then those citizens would be more sympathetic and supportive of industrial causes and needs. The dynamic character of technology had the potential to open new possibilities for the idea of progress in business, politics, and society. At the same time, big business forced a rethinking of public relations and corporate imagery for individual exhibits.

Fair organizers expressed very strong ideas about how best to translate the fair theme of science and progress into exhibits. They suggested ways that exhibit designers could highlight the concept of progress, and they urged designers to consider using innovative methods of display. Traditionally, superlatives reigned at world's fairs, and Chicago in 1933 was no exception. Visitors could be amazed by the world's largest thermometer, at 218 feet tall, a minute Bible that fit into a teaspoon, and the largest painting in the cyclorama of World War I. They could view the oldest locomotive, the fastest Zephyr train, and the first gondola to reach the stratosphere.

But fair organizers asked that corporate sponsors and exhibit designers do even more to attract and hold the interest of the crowds. They wanted displays that showed movement and told a story of the application of pure science to industry. During the previous forty years, the bond between science and industry had created many new industries that had quickly implemented new scientific discoveries. By promoting that angle-applying scientific knowledge to industry and agriculture - the fair could mark not only Chicago's hundred years of progress but also that of the entire world, as well as point to the future.

"Progress," as a theory, involves a synthesis of all things past, and a sense of optimism for the future. In other words, humans slowly but persistently advancing toward general happiness. The very notion of progress suggested buoyancy, hope, and resilience for Chicago and its future. The intersection of science, industry, and progress at the 1933 fair included a distinctively new notion of moving forward for a world traumatized by the economic crisis of the Great Depression. Following the expansion of big business and World War I, the idea of progress had shifted from a socially driven to a materially driven idea of progress, linked to industry's scientific 
and technological advances. Many Americans now saw the machine itself as a symbol of progress and social promise.

Exhibit designers translated the ideas of fair organizers in a variety of ways to promote their own industries. Ephemera saved by visitors at the fair provides the best source for illustrative examples and supporting explanations of these exhibition techniques: employ progress rhetoric; contrast the old against the new; create dioramas and models with movement; demonstrate production of products; and evoke modernism through streamlining and design.

Advertising and brochure writers used "progress rhetoric" to sell products, corporate brand images, and nationalistic visions. A Chevrolet booklet portrayed the automobile manufacturer together with two fashionable women, one at the steering wheel of a new Chevy, leading "the Parade of Progress" (see figure 1). Brochures promoted advances in everything from gelatin desserts to baby food. The Italian government distributed "Ten Years of Italian Progress" brochures, to reinforce air technology as symbolic of its government and Italy's resiliency and vitality, despite the Depression in Europe and America.

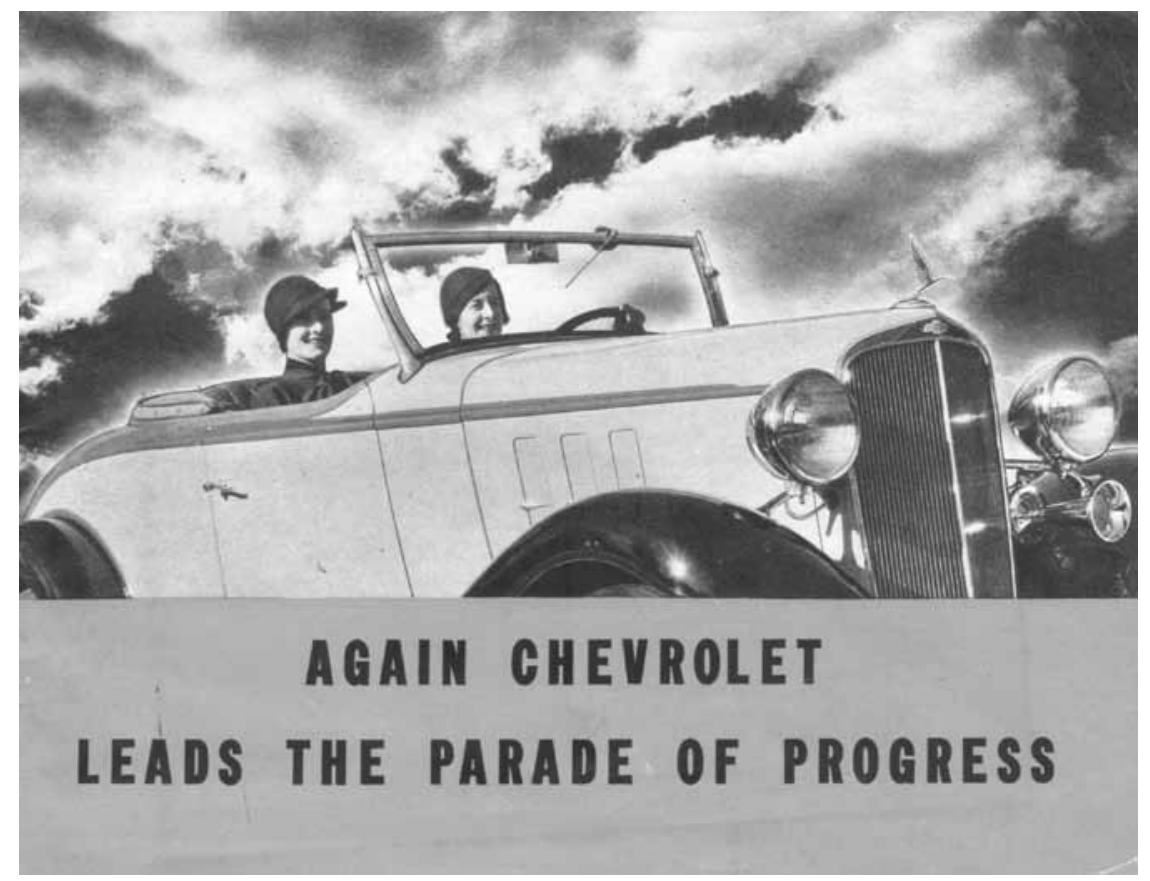

Figure 1. General Motors identified its technological and marketing successes in the automotive industry with the progress of women's rights on this complimentary handout. 
Contrasting the old with the new emphasized scientific advances, especially during the previous century of industrial revolution, and it generated optimism for a better future (see figure 2). Model kitchens from different eras illustrated ways in which homemaking and its drudgery had changed, while promoting the latest electrical appliances. Postage stamps showed how the federal government had shifted its local architecture from a protective Fort Dearborn in pioneer days to a modern skyscraper fair structure representing the three branches of government. A replicated Native American village with tribal members in residence for the duration of the fair stood in contrast to the General Motors pavilion, with its auto assembly line hall producing twenty-five "Master Six" coaches each day.

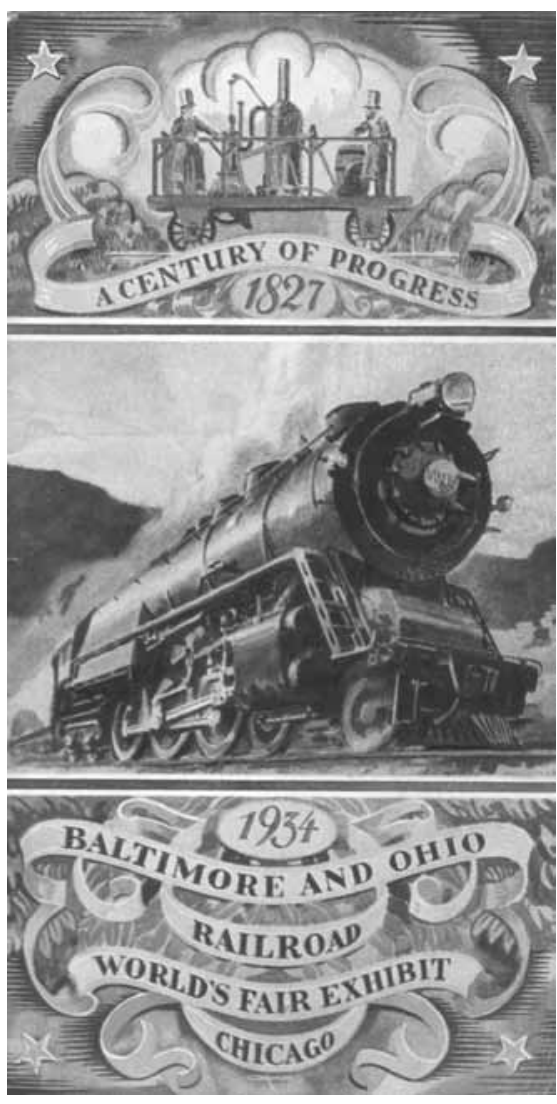

Figure 2. On the cover of its promotional brochure, the Baltimore \& Ohio Railroad Company contrasted its pioneer engine with the Capitol Limited locomotive of the first air-conditioned train between Chicago and New York.
Models with movement provided a sensational new way of telling a story. A diorama studio was located on the fairgrounds, and private fabricators constructed dioramas, including Fort Dearborn in 1833, Native Americans tribes in natural settings, Alaskan natural resources, Galapagos Islands biology, grain elevators, Niagara Falls, and a ninety-foot-long panoramic landscape illustrating urban and rural generation, transmission, and distribution of electricity for private, municipal, and industrial use. Model fabricators created dinosaurs engaged in deadly combat to remind fairgoers that Sinclair Refining Company used the oldest crude oils to make the finest lubricants for their automobiles, as well as Willie the robot, who talked and even smoked for Westinghouse Electric and Manufacturing Company.

Factory line demonstrations offered fair visitors an engaging lesson, often accompanied by samples for souvenirs. In addition to the popular Chevrolet automobile assembly line, demonstrations of stamping steel, rolling cigars, producing tires, making tubes of toothpaste, butchering beef, assembling shirts, and bottling beer captured the visitor's imagination. Visitors took home hosiery, tin cans, 
miniature bottles of whisky, and IBM punched cards (see figure 3). The memory of the demonstration, together with the mementos of the experience, forged strong consumer brand loyalty.

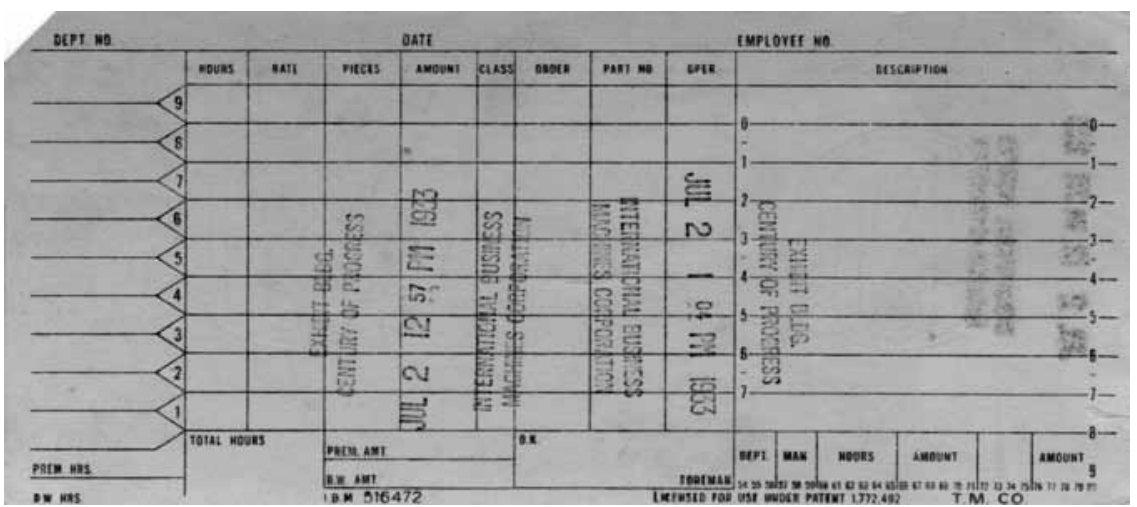

Figure 3. To demonstrate efficiency in the business world, International Business Machines Corporation (IBM) exhibited models of over seven hundred machines, giving away time card souvenirs that compared employee hours with output.

Exhibits replicated the sleek modernism of the architecture through streamlining, color, and lighting styles that today are often referred to as "Art Deco." Coca Cola bottling and spot welding demonstrations took place in futuristic display booths. Perhaps the most successful use of modernism to sell the idea of progress and optimism was the 1934 Ford Motor Company’s "Rotunda" and exposition buildings. Walter Dorwin Teague, an industrial designer, shifted the importance of the Ford

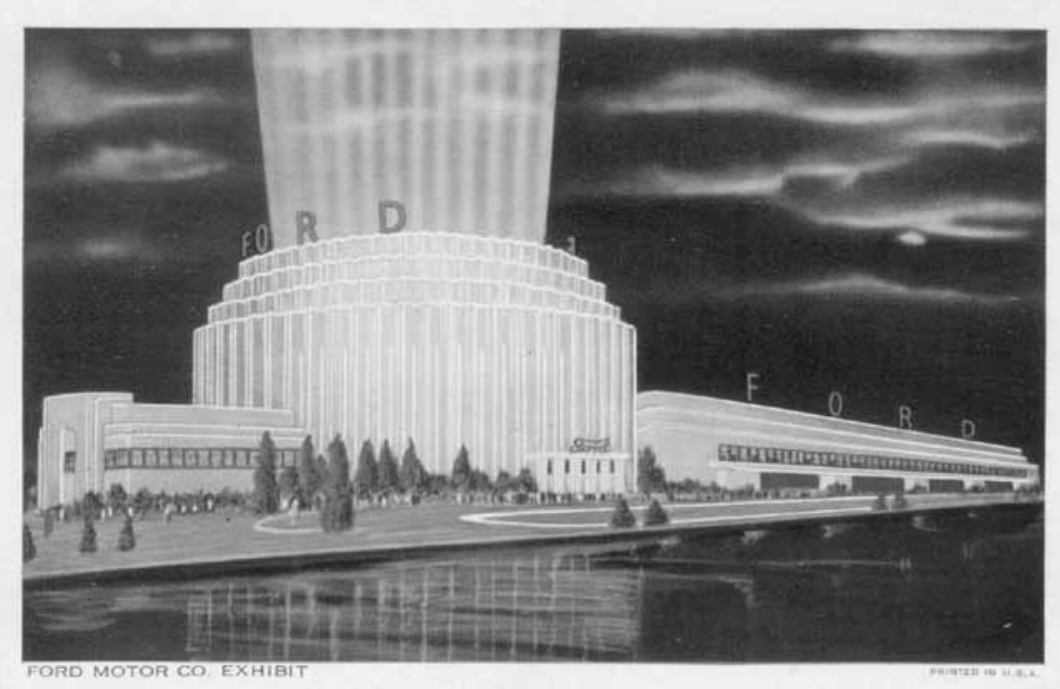

Figure 4. Postcards featured popular exhibits and sites such as the central pillar of light from the Ford Motor Company's gear wheel "Rotunda," piercing the sky for a mile with a promise of bright prosperity. 
pavilion from the architecture to the exhibits. Ford sold the motor company's corporate image through entertainment, drama, and style by simplifying and romanticizing the message to impress consumers. The Ford complex's domed, circular pavilion represented the giant cogs on a gear wheel. Inside the ten-story rotunda, twenty-foot-tall photomurals illustrated the workings of Ford industrial sites. Each evening, a light show featuring roof-mounted searchlights produced an amazing light beam that pierced the heavens with a promise of bright prosperity, magnifying Ford's visibility and dominance (see figure 4).

The Chicago World Fair's greatest legacy is that it provided the first showplace in which corporations could vie solely for the consumer's attention rather than for industrial prizes-in short, fair organizers reinvented the world's fair concept with this shift in vision. With the world traumatized by economic crisis, the fair created and widely broadcast a pioneering notion of progress, which set the trajectory for future fairs and expositions.

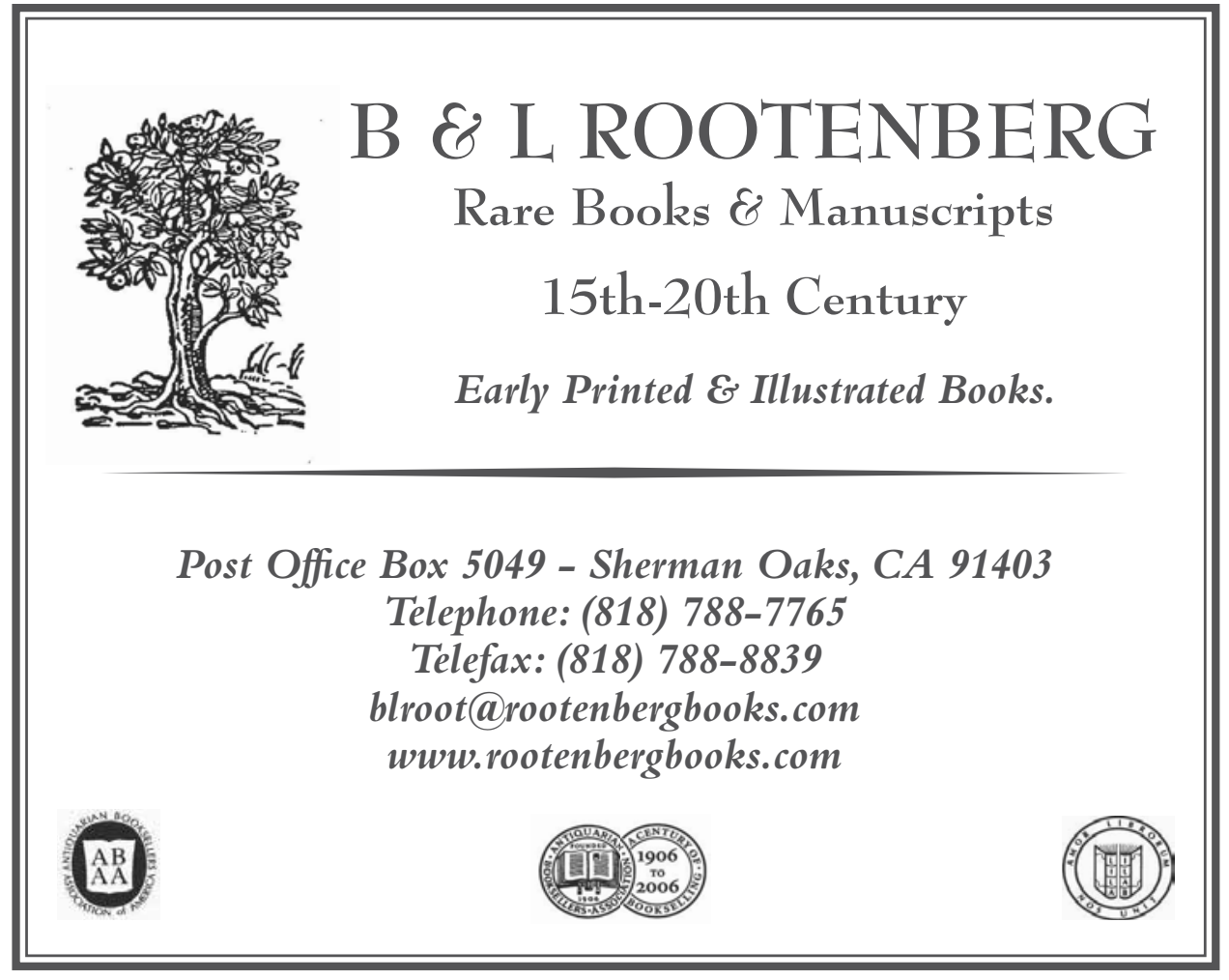

